\title{
Wikis: Developing pre-service teachers' leadership skills and knowledge of content standards
}

\author{
Angelia Reid-Griffin ${ }^{1 *} \&$ Kelli M. Slaten ${ }^{1}$ \\ ${ }^{1}$ University of North Carolina Wilmington, USA
}

\begin{abstract}
In this initial phase of our multi-year research study we set out to explore the development of leadership skills in our pre-service secondary teachers after using an online wiki, Wikispaces. This paper presents our methods for preparing a group of 13 mathematics and 3 science secondary pre-service teachers to demonstrate the essential knowledge, skills and dispositions of beginning teacher leaders. Our findings indicate the pre-service teachers' overall satisfaction with demonstrating leadership through collaborative practices. They were successful in these new roles as teacher/collaborator within the context of communication about content standards. Though the candidates participated in other collaborative tasks, this effort was noted for bringing together technology, content standards and leadership qualities that are critical for beginning teachers. Implications for addressing the preservice teachers' development of leadership skills, as they become professional teachers will be shared.
\end{abstract}

\author{
Keywords \\ teacher leadership \\ STEM preservice education \\ mathematics education \\ science education \\ technology \\ collaborations

\begin{aligned} & \hline Received: 4 Feb 2016 \\ & Revised: 7 Feb 2016 \\ & Accepted: 8 Feb 2016 \\ & Published online: 03 Mar 2016 \\ & \hline\end{aligned}

DOI: $10.20897 /$ lectito.201601

\section{INTRODUCTION}

Using wikis for communicating with peers is not new for many undergraduate students. For a particular group of 16 secondary pre-service teachers, it creates a unique method for developing and demonstrating leadership qualities. Wikis are defined as collections of sites on the web that can be easily edited online (Moskaliuk \& Kimmerle 2009; Leuf \& Cunningham 2001). The popular educational wiki site, Wikispaces, was utilized in a class of 13 secondary mathematics and 3 science pre-service teachers to share instructional products aligned with Common Core State Standards in Mathematics (CCSSM) and the North Carolina Essential Science Standards (NCESS) (Common Core State Standards Initiative 2010; NC Department of Public Instruction 2010).

As the instructors of a secondary education seminar course, we sought an innovative approach to allow pre-service teachers to develop and demonstrate teacher leadership skills in response to state teaching evaluation standards, the North Carolina Professional Teaching Standards (NCPTS) (NC State Board of Education 2007). These standards were written to guide the evaluation of practicing teachers. Bond (2011, p. 11) noted the limited amount of research on leadership for pre-service teachers and the critical need "to equip our pre-service teachers with the knowledge, skills, and dispositions for teacher leadership roles" in teacher education programs. We recognized the need to address the development of leadership skills with pre-service teachers before they become practicing teachers. Using the primary themes to demonstrate the leadership skills as described by York-Barr and Duke (2004, p. 282), we began to establish the tasks to support the development of the candidates. The themes are as follows: "continuing to learn about and demonstrate

${ }^{*}$ Correspondence to: griffina@uncw.edu 
advanced curricular, instructional, and assessment practices; school culture and how to initiate and support change and developing the knowledge and skills to support the development of colleagues". The wiki class space, provided a learning community in which the pre-service teachers were able to build, edit, contribute, and share ideas related to their own instructional practices and resources grounded in curriculum standards. As noted by Twu (2009), the tool offers valued social interactions that occur in learning environments rich in both social and cultural perspectives. The instructional strategies explained by Twu (2009) indicate the vital role of the instructor in providing support for learners to interact, getting familiar with the tool, and communicating within this collaborative context.

We found that the tool offered a platform for the thoughtful exchange of ideas. Bringing together technology, content standards and leadership qualities, we developed a task to enhance the pre-service teachers' pedagogical and teacher leadership skills. This article addresses the role of using wikis as a tool in demonstrating knowledge of CCSSM, NCESS, NCPTS and the development of leadership skills by focusing on a design method used to teach pre-service mathematics and science teachers to plan effectively and demonstrate teacher leadership qualities.

\section{LITERATURE}

Why wikis? The decision to use Wikispaces was based on our personal interests in technology and experiences with using wikis and other Web 2.0 technologies in educational settings. We agreed the Wikispaces design and usability would serve as the platform for helping our pre-service teachers develop pedagogical and leadership skills. Wikispaces "makes collaboration and community building easy and encourages the use of a myriad of Internet resources, content, and tools (Wikispaces Classroom 2013). We found, as Désilets, Paquet and Vinson (2005), that it did not require any special software or hardware, which made it a viable choice for use in the course and in our high schools. The collaborative nature of the wiki classroom space made it a valuable technology for teaching and learning (Kohler \& Fuchs-Kittowski 2005).

Another reason for selecting this particular wiki was its account properties. It allows users access to materials as long as the wiki is kept active, a benefit for both instructors and pre-service teachers. After setting up the class space, account users still have access to their work after completing the teacher education program. Former pre-service teachers are able to access materials, and continue to edit, collaborate and share with peers while they work in their own secondary classrooms. This technology, grounded in socio-cultural interactions, provides a continual space for instructors and students to construct, collaborate, edit and discuss instructional ideas (Twu 2009). Wikispaces for the leadership assignment allowed them to create the product, share it and provide comments on others' content on the site. Reinhold's (2006, p. 47) suggestion that "wikis facilitate collaborative shaping and sharing of knowledge" aided our decision.

\section{METHOD}

We designed the leadership assignment to address the curriculum standards for developing instructional resources using this tool. The assignment helped the pre-service teachers better understand teacher leadership qualities through reflective practices and sharing of resources with teachers. As a result of completing this assignment, the pre-service teachers were able to build confidence and skills through taking ownership in sharing knowledge with others. The assignment provided our pre-service teachers the opportunity to build on their understanding of the CCSSM and NCESS standards and shape how they shared resources. According to Evans (2006), wikis are tools that enable groups to harness their creative energy through shared knowledge. Each pre-service teacher created an individual page in the wiki showcasing their understanding of standards with a lesson plan and list of online resources. They subsequently shared their pages with their partnership teachers and peers for feedback. We were able to create a collaborative online community in which pre-service teachers were able to "generate online materials that reflect what they have learned and show connections between their prior knowledge, the course content, and their personal experiences" (Matthew \& Callaway 2009, p. 52). The development of leadership skills resulted from the pre-service teachers' collectively taking ownership of their finished projects, sharing their work with others, and valuing the comments and contributions from others. Following a supported process to ensure they had quality teaching and learning from teacher leaders in the schools, led to this intended effect of improved instructional practices and quality leadership skills. Figures 1 and 2 show the layout of class wiki with student samples. 


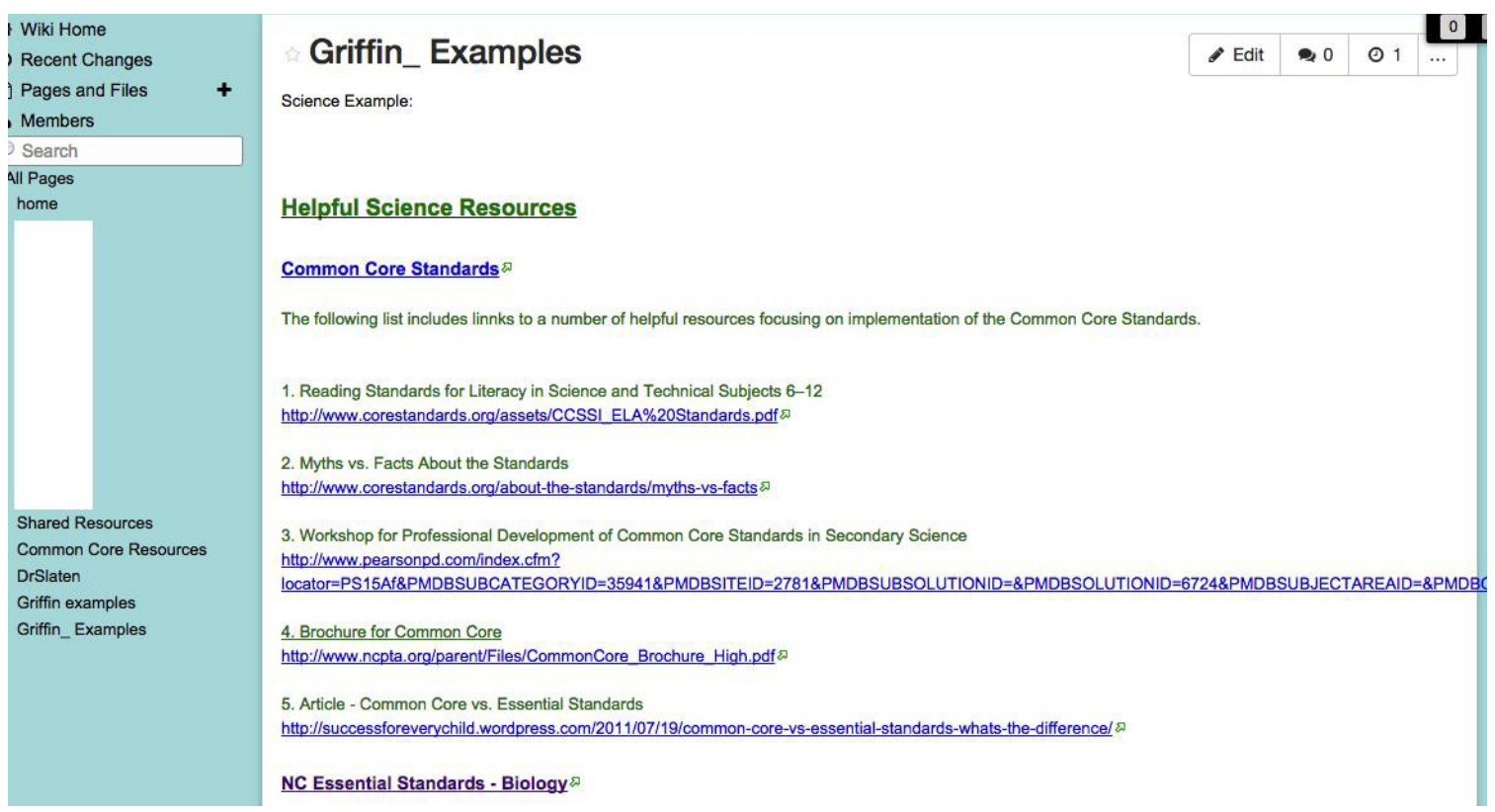

Figure 1. Wiki page science example (p. 4)

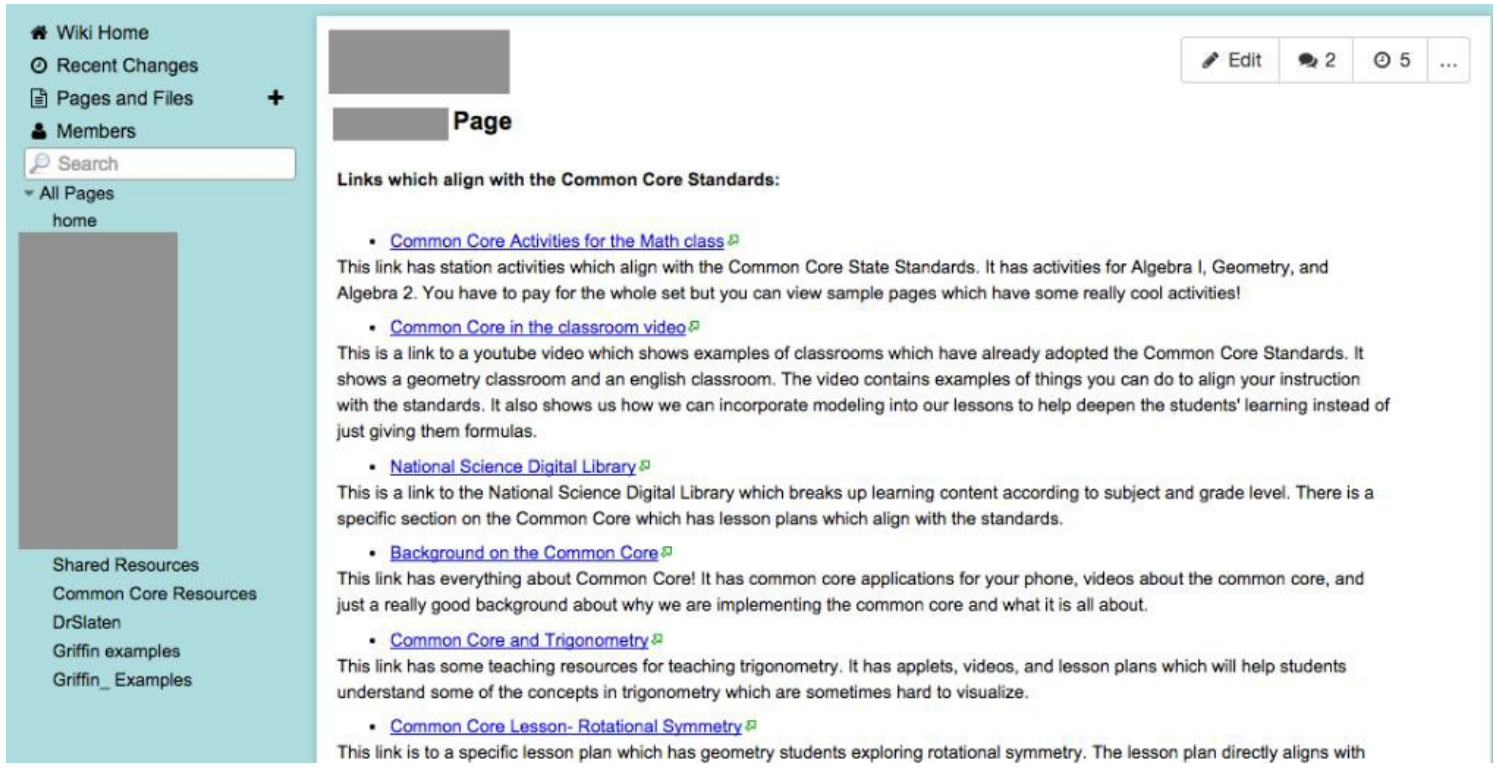

Figure 2. Wiki page mathematics example (p. 4)

The leadership assignment was designed to help pre-service teacher candidates in mathematics and science demonstrate Standard 1c of the NC Professional Teaching Standards, which require teachers to lead within the teaching profession. Based on this standard, all candidates should: "Strive to improve the teaching profession; contribute to the establishment of positive working relationships in the school; actively participate in and advocate for the decision-making structures in education and government that take advantage of the expertise of teachers and promote professional growth for all educators and collaborate with their colleagues to improve the profession" (NC State Board of Education 2007, p. 2). Being a teacher leader is an important quality for educators and in order for teacher candidates to pursue such an endeavor, they must be able to reflect upon, analyze, and share their interests, knowledge, skills and dispositions with others.

Using the guidelines provided and in-class tutorial on using the class wiki, the pre-service teachers were able complete the assignment based on sound pedagogy. The pre-service teachers were asked to complete an anonymous Likert scale perceptions survey item to assess their attitudes about using the tool and their confidence in demonstrating leadership qualities in the schools. They rated their confidence high with using the tool and satisfaction with leadership qualities demonstrated from the task. 
The basis of the leadership assignment was to create an environment supportive of "collaborative shaping and the sharing of content and pedagogical knowledge" (Reinhold, 2006, p. 47). The presence of the wiki tool provided the caveat for the pre-service teachers to demonstrate the quality of a being a teacher leader in the teaching profession. It also allowed for a sustained learning environment through the reflective exchange of knowledge by pre-service teachers, instructors and partnership teachers. The tiered levels of participation in the assignment allowed the pre-service teachers to actively communicate with others who have common interests and commitment to the teaching profession. The task energized the thinking of our partnership teachers and provided the pre-service teachers with new roles in the internship process. Pre-service teachers were rethinking their commitment to the profession. It offered the pre-service teachers a "sense of collective responsibility" that is acquired only when one commits honesty (Ackerman \& Mackenzie 2006, p. 70).

\section{RESULTS}

When presented with broader roles and responsibilities, pre-service teachers may redefine their own thinking about teaching and "when instruction is public, teachers learn about the power of collaboration for improving their practice" (Paek 2008, p. 12). The comments shared on individual products provided insight into how the materials could be effectively used in a secondary mathematics or science classrooms. Ackerman and MacKenzie (2006) assert the importance of allowing teacher leaders the opportunity to voice their opinions. The ability to post comments using the wiki enabled the pre-service teachers and their partnership teachers to state their opinions while remaining focused and share ideas to extend knowledge of content and standards.

\section{Pre-service teacher comments (Pre-service Teacher Comments, 2012)}

I really like this matrices activity and I think it goes along well with the common core curriculum.

I really like how you incorporated science into this activity as well. This may help peak certain students interests, particularly those who enjoy science. Great job!

Hey, great resources. I'm not science but I liked the way you organized your page. Loved your lesson plan as well.

Factoring is something many of my students struggled with especially since there are so many different techniques used to factor. I really think it is important to distinguish between the different techniques so that the students are using the easiest method for the given polynomial, which is why I really enjoyed this lesson.

\section{Partnership teacher comments (Partnership Teacher Comments, 2013)}

Instead of giving the students just the table, go through and give them step-by-step instructions on how to calculate things and then they can plug it into the table."

Have the students make the graph themselves instead of giving them the graphs. Overall this is a great discovery activity that relates new material to prior knowledge of inverses, which the students can see in their everyday lives.

Encouraging this exchange of ideas, the leadership assignment provided an ideal opportunity for preservice teachers to develop and demonstrate leadership qualities. The pre-service teachers and partnership teachers were provided with a new outlet for collaboration and critical thinking. The success was due in part to its collaborative structure of engaging participants in conversations with influential support. The assignment created an opportunity for constructive feedback. The level and depth of feedback the pre-service teachers exchanged with one another was rather surface, lacking in constructive criticism, whereas the partnership teachers and instructors provided more directed feedback. Many pre-service teacher comments included "I like" or "I love". This pattern of feedback constrained their engagement in critical thinking and reflective practices with their peers.

\section{DISCUSSION}

Lewthwaite (2006) noted, in his study of science teacher leaders, the following factors are needed to develop teacher leader qualities: "professional knowledge, teaching efficacy, interest, motivation and commitment" (p. 343). The pre-service teachers in this course were able to demonstrate all of these traits through the use of this tool. The multi-leveled exchange of ideas by the pre-service teachers, partnership teachers and instructors led to a successful teacher-leadership practice that can be modeled in other discipline areas. 
Overall, the pre-service teachers were successful in completing the leadership assignment and demonstrating the teacher leadership quality of leading the profession. The noted success of implementing this assignment in the course was the novel platform of innovative thinking and exchanges of content knowledge and pedagogy. This led to energized thinking by the pre-service teachers, their partnership teachers, and the course instructors through the sharing of new ideas and practices. The wiki class space provided the ideal platform for formative comments on instructional content developed by the pre-service teachers. The pre-service teachers commented they took this opportunity to share their wiki pages with other novice educators and teachers in their placement schools, indicating a rethinking of their roles within the schools. Through this opportunity the pre-service teachers were able to lead and rethink their commitment within the teaching community. As Ronald (2001) suggested in his work on teaching communities, the wiki in this setting also supports the idea that "teaching always occurs in a community of other teachers, as well as in a community of learners" (p. 318). We are pleased with the results and the confidence of the pre-service teachers in using this tool to demonstrate leadership traits.

Limitations of time and coaching on constructive feedback impacted the pre-service teachers' sharing and conversations with peers, partnership teachers and others. Pre-service teachers need further instruction on providing constructive feedback to their peers. There is a need for more research on the use of wikis in secondary education programs to determine the level of influence this could have on pre-service teachers' development of leadership characteristics.

\section{REFERENCES}

Ackerman, R. and Mackenzie, S.V., 2006. Uncovering teacher leadership.Educational Leadership, 63(8), pp. 66-70.

Bond, N., 2011, October. Preparing preservice teachers to become teacher leaders. The Educational Forum, 75(4), pp. 280297.

Common Core State Standards Initiative, 2010. Common Core State Standards for Mathematics. Washington, DC: National Governors Association Center for Best Practices and the Council of Chief State School Officers.

Désilets, A., Paquet, S. and Vinson, N., 2005. Are wikis usable? Paper presented at the WikiSym 2005 Conference Proceedings -International Symposium, 16 October. ACM Press, New York, 3-15.

Evans, P., 2006. The wiki factor. BizEd, 5(2), pp. 28-32.

Köhler, A. and Fuchs-Kittowski, F., 2005. Integration of communities into process-oriented structures. J. UCS, 11(3), pp. 410-425.

Leuf, B. and Cunningham, W., 2001. The Wiki way: quick collaboration on the Web. Addison-Wesley, Boston.

Lewthwaite, B., 2006. Constraints and contributors to becoming a science teacher-leader. Science Education, 90(2), pp. $331-347$.

Matthew, K.I., Felvegi, E. and Callaway, R.A., 2009. Wiki as a collaborative learning tool in a language arts methods class. Journal of Research on Technology in Education, 42(1), pp. 51-72.

Moskaliuk, J., Kimmerle, J. and Cress, U., 2009. Wiki-supported learning and knowledge building: effects of incongruity between knowledge and information. Journal of Computer Assisted Learning, 25(6), pp. 549-561.

NC Department of Public Instruction, 2010. NC essential standards for science (9-12). Available at: http://www.ncpublicschools.org/acre/standards/new-standards/ . (Accessed 12 July 2012).

NC State Board of Education, 2007. North Carolina educator evaluation system: Teacher candidate evaluation rubric. Available at: http://www.ncpublicschools.org/docs/ihe/remodeling/teacher/pre-service-teacherrubric.pdf (Accessed 12 July 2011).

Paek, P.L., 2008. Practices worthy of attention: Improving secondary mathematics teaching and learning. NCSM Journal of Mathematics Education Leadership, 10(1), pp. 9-14.

Partnership Teacher Comments. (2013). [Wiki] Wiki log comments. Available at: http://wikispaces.com/ [Accessed 22 Apr. 2013]

Pre-service Teacher Comments. (2012). [Blog] Wiki log comment. Available at: http://wikispaces.com/ [Accessed 27 Apr. 2012].

Reinhold, S., 2006. WikiTrails: Augmenting wiki structure for collaborative, interdisciplinary learning. In Proceedings of the 2006 international symposium on Wikis (pp. 47-58) ACM.

Ronald, K., 2001. "Befriending" other teachers: communities of teaching and the ethos of curricular leadership. Pedagogy, 1(2), pp. 317-325.

Twu, H., 2009. Effective wiki strategies to support high-context culture learners. TechTrends, 53(5), pp.16-21.

York-Barr, J. and Duke, K., 2004. What do we know about teacher leadership? Findings from two decades of scholarship. Review of educational research, 74(3), pp. 255-316. 